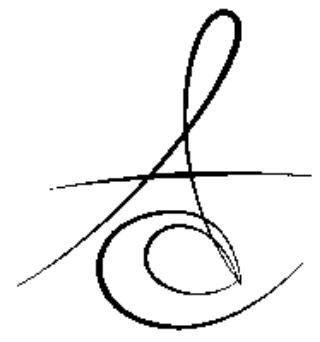

Makale Kodu/Article code: 2204

Makale Gönderilme tarihi: 20.03.2015

Kabul Tarihi: 22.04.2015

\section{TÜKÜRÜK BEZİ PATOLOJİLERİNİN TEŞHİSİNDE ULTRASONUN TANI DEĞERİ}

\author{
THE DIAGNOSTIC VALUE OF ULTRASOUND IN SALIVARY GLAND \\ PATHOLOGIES
}

\author{
Doç. Dr. Fatma ÇAĞLAYAN*
}

\section{ÖZET}

Amaç: Bu çalışmanın amacl, enfeksiyon, taş, tümör, kist gibi tükürük bezi patolojilerinin değerlendirilmesinde Ultrasonografi(USG)'nin tanısal etkinliğini değerlendirmektir.

Materyal Metod: Çalışma kapsamında, kliniğimize başvuran hastalardan alınan anamnez ve yapılan klinik muayeneler sonucunda, tükürük bezi patolojisi ön tanısı konulan 19 hastaya rutin uygulanan konvansiyonel radyografi işlemlerinin ardından USG incelemesi yapılmıştır.

Bulgular: Bu hastalardan 7(\%37) tanesinde konvansiyonel radyografi tetkikleri ile herhangi bir bulgu bulunamazken, USG incelemesi sonucunda bu hastaların tanıları konulmuştur. Hastalarımızın yalnızca 1 tanesinde ultrasonografide herhangi bir bulgu bulunamamıştır. Ayrıca konvansiyonel radyografi tetkikleri ile sialolithiasis ön tanısı konulan 12 hastanın 3'ünde, USG ile kalsifikas- yonların tükürük bezleri ile ilişkili olmadığı tespit edilmiştir.

Sonuç: Ultrasonografi $18(\% 95)$ hastada kesin tanıya katkı sağlamıştır.

Anahtar Kelimeler: Tükürük bezleri; Konvansiyonel radyografi; Ultrasonografi.

\section{ABSTRACT}

Aim: The aim of this study was to evaluate the diagnostic value of ultrasonography(USG) in salivary gland pathologies such as infection, sialolithiasis, tumor and cyst.

Material Method: According to scope of study, 19 patients who were initially diagnosed to have salivary gland pathology as a result of clinical examination in our clinic, were examined by USG after routine conventional radiography techniques.

Results: While it was not found any pathology in $7(37 \%)$ of these patients by conventional radiography, they were diagnosed by USG. Only 1 of our patients revealed no finding by USG. In addition, it was detected by USG that, the calcifications were not related with gland parenchyma in 3 of 12 patients who were diagnosed as sialolithiasis by conventional radiography.

Conclusion: In conclusion, USG contributed to final diagnose in $18(95 \%)$ patients.

Key words: Salivary glands; Conventional radiography; Ultrasonography.

\section{GİRİş}

Tükürük bezi hastalıklarının radyolojik incelemelerinde konvansiyonel radyogramlar sadece radyoopak görünümlü sialolithiazis vakalarında yararlıdır. Tükürük kanallarının durumu biraz daha net bir şekilde incelenmek istendiğinde sialografi çekilebilir. Fakat sialografi akut enflamatuar durumlarda ve iyot alerjisi olan kişilerde kontrendike olup, uygulaması zaman alan ve hasta için kolay kabullenilemeyen bir yöntemdir. ${ }^{1}$ Bu yöntemlerle kıyaslandığında ultrasonografi non-invaziv bir yöntem olduğu ve tükürük bezi patolojilerinin tümünün (opak veya non-opak taşlar, enfeksiyon, kist, tümör vb.) değerlendirilmesine imkan sağladığı için sıklıkla kullanılan ve yararı bir tetkiktir. ${ }^{2,3}$

Tükürük bezi patolojilerinde en sık görülen klinik semptomlar ağrı, ağız kuruluğu veya tükürük fazlalığı ve şş̧liktir. Bezde yemek esnasında ortaya

\footnotetext{
* Atatürk Üniversitesi, Diş Hekimliği Fakültesi, Ağız Diş ve Çene Radyolojisi AD.
} 
çıkan ağrı ve dolgunluk hissi, tıkanıklı̆ı düşündürür. Enfeksiyon veya enflamasyonda ağrının yemekle ilgisi yoktur ve daha uzun süre devam eder. Yemek esnasında ortaya çıkan ve öğünler arasında kaybolan bir şişlik, kanalda tıkanıklı̆ı düşündürür. Tekrarlayan parotitis gibi enfeksiyonlar bezde aralıklı büyümeye yol açar, fakat tükürük bezi kanalında tıkanıklık yoktur. Kalıcı şişlik tümörden veya Sjögren Sendromu gibi sistemik bir hastalıktan dolayı olabilir. Şişliğin bilateral oluşu genellikle kabakulak veya endokrin bozukluk gibi sistemik bir hastalığı düşündürür.

Tükürük bezi hastalıklarının tanısında en sık kullanılan görüntüleme yöntemleri konvansiyonel radyografiler, ultrasonografi (USG), sialografi, sintigrafi, bilgisayarlı tomografi(BT) ve magnetik rezonans görüntüleme(MRG)dir. ${ }^{1}$ Işın geçirmeyen (radyoopak) taşlar, genellikle konvansiyonel radyografilerde görülebilir. Submandibüler taşların \%20'si, parotis taşlarının $\% 80$ 'i ışın geçirir (radyolusen) ve radyografilerde görülemezler. Taşların \%80-90'ı submandibüler bezde bulunur. Submandibüler bölgenin düz grafileri mevcut olan herhangi bir taşı gösterebilir. Parotis bölgesinde ise düz filmler fazla bilgi vermez. Altta bulunan kemik yapı ve taşların küçük ve ışın geçirgen oluşları, bunları tespit etmeyi güçleştirir. Sialografi kanal sistemini değerlendirmekte çok faydalıdır. Diğer taraftan, özellikle küçük ve bezin dışındaki kitlelerde, sialografinin yeri sınırlıdır. Sintigrafi, en fazla parotis bezinde ve teknezyum kullanılarak yapilır. ${ }^{1}$ Radyoizotop tarama, parankim fonksiyonunu ve yer kaplayan lezyonları belirlemekte kullanılır. BT, tükürük bezi içindeki veya çevresindeki kitlelerin belirlenmesinde tercih edilecek görüntüleme yöntemidir. Bir kitlenin büyüklüğünü, bezin içinde mi dışında mı olduğunu daha iyi belirler ve tükürük taşlarını hassas bir şekilde gösterir. Fakat, siyalektazi veya tıkanıkığı göstermekte sialografiden daha az güvenilirdir ve bez fonksiyonu hakkında bilgi vermez. MRG yumuşak dokulardaki lezyonları ayırt etmekte kullanılan mükemmel bir görüntüleme tekniğidir. MRG'nin dezavantajı ise kemik yapıyı göstermemesidir. Bundan dolayı, kemiğin içinde ve etrafındaki lezyonları göstermekte BT ve MR birlikte kullanılır.

USG tükürük bezi patolojilerinin tanısı için değerli ve faydalı bir yöntemdir. Teşhis amaçlı ultrason tükürük bezlerini, bilhassa parotisin yüzeysel lobunu, incelemekte kullanılan çabuk, ucuz, zararsız ve kolay bir yöntemdir. Sadece herhangi bir kitle olduğunda bunun doğrulanması için değil, aynı zamanda altta yatan sebepleri göstermede de etkin bir yöntemdir. ${ }^{3}$ Kalsifikasyonların yumuşak dokularla olan ilişkisi kolaylıkla belirlenir. Solid veya kistik lezyonların ayırımı yapılabilir. Parankimin homojenitesi ve kan akımı değerlendirilebilir.

\section{GEREÇ VE YÖNTEM}

Bu çalışma Atatürk Üniversitesi Diş Hekimliği Fakültesi Dekanlığı Etik Kurulu tarafından onaylanmıştır(Sayı: 016/2011). Atatürk Üniversitesi Diş Hekimliği Fakültesi Ağız, Diş ve Çene Radyolojisi kliniğine başvuran, anamnez ve klinik muayeneleri sonucunda tükürük bezi patolojisi ön tanısı konulan 19 hasta çalışmaya dahil edilmiştir. Tükürük bezlerinde patoloji bulunan hastalar sıklıkla bezde yemek esnasında ortaya çıkan ağrı ve dolgunluk hissi, yemek esnasında ortaya çıkan ve öğünler arasında kaybolan veya tümör varlığında kalıcı olan şşslikler, tükürük salgısında artma veya azalma gibi bulgularla gelirler. Bu hastaların tükürük bezlerine yönelik olarak anamnez ve klinik muayeneleri gerçekleştirilmiş̧ir. $\mathrm{Bu}$ hastaların inspeksiyon ve palpasyonla klinik muayeneleri derinleştirilmiş, ağız tabanı, peritonsiller bölge, parotis ve submandibular kanallar, bimanuel muayene ile değerlendirilmiştir. Parotis ve submandibüler bez kanallarının ağzı incelenip tükürük akışı, kanal ağızlarında kızarıklık, enfeksiyon veya cerahat akışı olup olmadığı tespit edilip, tüm klinik bulgular, hastaların yaşı, cinsiyeti ve varsa ilave sistemik hastalıkları not edilmiştir.

Daha sonra kliniğimizde bu hastalar için rutin olarak uygulanan okluzal radyografi veya panoramik radyografi gibi konvansiyonel radyografi teknikleri uygulanıp, elde edilen bulgular not edilmiş. Ardından ultrasonografi uygulamasına geçilmiştir. USG incelemeleri kliniğimizde bulunan Toshiba markalı Applio 300 (Toshiba Corporation, Tokyo, Japan) model cihaz ile $7,5 \mathrm{MHz}$ lineer prob kullanılarak, transversal ve longitidunal düzlemlerde, extra-oral olarak gerçekleştirilmiştir. İncelemeler genel olarak (parankimal ve duktal yapılar, kalsifikasyonlar ve patolojiler) B-mod USG, kan akımları renkli doppler USG ile değerlendirilmiştir. İncelemeler sonucunda elde dilen görüntüler araştırmacı tarafından değerlendirilmiştir. Bez parankimleri, kanalları ve kan akımları değerlendirilip, elde edilen bulguları da kaydedilmiştir. Sonuçta her iki yönteme göre elde edilen bulgulara göre ultrasonografinin tanısal etkinliği değerlendirilmiştir. 


\section{BULGULAR}

Çalışmaya 5 kadın 14 erkek olmak üzere toplam 19 hasta dahil edildi. Hastaların tamamı anamnez ve klinik muayeneleri sonucunda tükürük bezi patolojisi ön tanısı konulan hastalardan oluşuyordu. Hastalarımızın 11 tanesinde ağrı, 10 tanesinde sert ve/veya yumuşak şişlik şikayeti varken, 4 tanesinde ise herhangi bir şikayet yoktu. Hastaların klinik muayeneleri sonucunda 3 tanesinde ağız tabanı palpasyonunda flüktan şişlik, 6 tanesinde intra-oral veya ekstra-oral palpasyasonda sert kitle(taş), 1 tanesinde kanal ağzında kızarıklık bulguları tespit edilirken, 8 tanesinde ise herhangi bir klinik bulgu tespit edilemedi. Daha sonra konvansiyonel radyolojik incelemeye geçildi. Konvansiyonel radyolojik inceleme sonucunda 7 hastada herhangi bir bulgu tespit edilemezken, 11 hastada anatomik yapılar üzerine süperpoze olmuş değişik ebatlarda kalsifik kitleler (Şekil 1) ve bir hastada submandibular bölgede mandibula angulusunda radyolusent lezyon tespit edildi. Daha sonra yapılan ultrasonografik incelemede 3 hastamızda herhangi bir bulgu görülmezken, 3 hastamızda akustik güçlenmeye sahip hipo-ekoik kistik lezyon(Şekil 2), 1 hastamızda submandibular lenfadenopati ve 12 hastamızda akustik gölgeye sahip hiper-ekoik kalsifik odaklar tespit edildi. USG de tespit edilen kalsifikasyonların 7 tanesinin submandibular bez parankimi veya Wharton kanalında (Şekil 3), 2 tanesinin parotis bezi Stenon kanalında olduğu tespit edilirken (Şekil 4), 3 tanesinin tükürük bezleri parankimleri veya kanalları ile ilişkili olmadıkları (Şekil 5) tespit edildi. Ayrıca submandibular gland içerisinde tespit edilen 2 taş vakasında aynı zamanda bez parankiminin homojen ekojenitesinde ve kanlanmasında bozulma tepsi edildi.

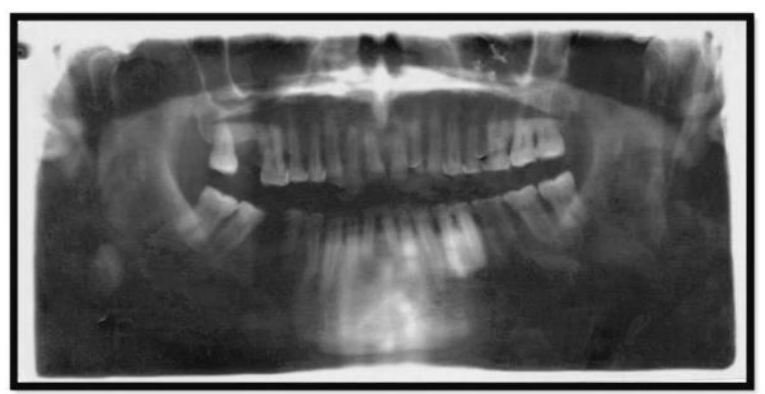

Şekil 1. Submandibular sialolithiaisis ön tanısı konulan bir hastanın panoramik görüntüsü
Tablo1. Hastaların klinik, radyolojik ve ultrasonografik bulguları.

\begin{tabular}{|c|c|c|c|c|c|}
\hline Hasta & Cinsiyet & Anamnez & Klinik bulgu & Radyolojik bulgu & USG \\
\hline 1 & $\mathrm{E}$ & Ağrı & - & - & - \\
\hline 2 & $\mathrm{~K}$ & Şişlik & $\begin{array}{c}\text { Ağız } \\
\text { tabanında } \\
\text { fluktan şişlik }\end{array}$ & - & $\begin{array}{l}\text { Ranula } \\
\text { Kistik }\end{array}$ \\
\hline 3 & $\mathrm{~K}$ & Şişlik & $\begin{array}{c}\text { Ağız } \\
\text { tabanında } \\
\text { fluktan şişlik }\end{array}$ & - & $\begin{array}{l}\text { Ranula } \\
\text { Kistik }\end{array}$ \\
\hline 4 & $E$ & $\begin{array}{l}\text { Ağrı ve } \\
\text { sert şişlik }\end{array}$ & $\begin{array}{l}\text { Palpasyonda } \\
\text { sert kitle }\end{array}$ & $\begin{array}{c}\text { Submandibular } \\
\text { bölg. } \\
\text { kalsifikasyon }\end{array}$ & $\begin{array}{l}\text { Submandibular } \\
\text { parankimal } \\
\text { sialolith }\end{array}$ \\
\hline 5 & $\mathrm{E}$ & $\begin{array}{l}\text { Ağrı ve } \\
\text { sert şişlik }\end{array}$ & $\begin{array}{l}\text { Palpasyonda } \\
\text { sert kitle }\end{array}$ & $\begin{array}{l}\text { Submandibular } \\
\text { bölg. } \\
\text { kalsifikasyon }\end{array}$ & $\begin{array}{c}\text { Submandibular } \\
\text { duktal } \\
\text { sialolith. }\end{array}$ \\
\hline 6 & $\mathrm{~K}$ & $\begin{array}{l}\text { Ağrı ve } \\
\text { şişlik }\end{array}$ & Palp. ağrı & - & - \\
\hline 7 & $E$ & $\begin{array}{l}\text { Ağrı ve } \\
\text { şişlik }\end{array}$ & - & $\begin{array}{c}\text { Submandibular } \\
\text { bölg. } \\
\text { kalsifikasyon. }\end{array}$ & $\begin{array}{l}\text { Submandibular } \\
\text { parankimal } \\
\text { sialolith }\end{array}$ \\
\hline 8 & $E$ & $\begin{array}{l}\text { Ağrı ve } \\
\text { sert şişlik }\end{array}$ & Palp. ağrı & $\begin{array}{l}\text { Submandibular } \\
\text { bölg. } \\
\text { kalsifikasyon }\end{array}$ & $\begin{array}{c}\text { Submandibular } \\
\text { parankimal } \\
\text { sialolith ve } \\
\text { bozulma }\end{array}$ \\
\hline 9 & $E$ & Ağrı & - & $\begin{array}{c}\text { Submandibular } \\
\text { bölg. } \\
\text { kalsifikasyon }\end{array}$ & $\begin{array}{l}\text { Submandibular } \\
\text { parankimal } \\
\text { sialolith }\end{array}$ \\
\hline 10 & $E$ & Ağrı & - & $\begin{array}{c}\text { Submandibular } \\
\text { bölg. } \\
\text { kalsifikasyon }\end{array}$ & $\begin{array}{c}\text { Submandibular } \\
\text { parankimal } \\
\text { sialolith. }\end{array}$ \\
\hline 11 & $E$ & - & - & $\begin{array}{l}\text { Angulusta } \\
\text { radyolusent } \\
\text { lezyon }\end{array}$ & - \\
\hline 12 & $\mathrm{E}$ & $\begin{array}{l}\text { Ağrı ve } \\
\text { sert şişlik }\end{array}$ & $\begin{array}{c}\text { Extraoral } \\
\text { palp. } \\
\text { Ağrı ve sertlik }\end{array}$ & $\begin{array}{l}\text { Submandibular } \\
\text { bölg. } \\
\text { kalsifikasyon }\end{array}$ & $\begin{array}{l}\text { Bez ile ilgili } \\
\text { olmayan } \\
\text { kalsifikasyon }\end{array}$ \\
\hline 13 & $E$ & $\begin{array}{l}\text { Ağrı ve } \\
\text { şişlik }\end{array}$ & $\begin{array}{l}\text { Stenon kanal } \\
\text { ağzında taş }\end{array}$ & $\begin{array}{l}\text { Maxiller bölg. } \\
\text { kalsifikasyon }\end{array}$ & $\begin{array}{l}\text { Parotideal } \\
\text { duktal } \\
\text { sialolith. }\end{array}$ \\
\hline 14 & $E$ & - & - & $\begin{array}{c}\text { Submandibular } \\
\text { bölg. } \\
\text { kalsifikasyon }\end{array}$ & $\begin{array}{l}\text { Bez ile ilgili } \\
\text { olmayan } \\
\text { kalsifikasyon }\end{array}$ \\
\hline 15 & $E$ & Şişlik & $\begin{array}{c}\text { Ağız } \\
\text { tabanında } \\
\text { fluktan şişlik }\end{array}$ & - & $\begin{array}{l}\text { Ranula } \\
\text { Kistik }\end{array}$ \\
\hline 16 & $\mathrm{~K}$ & Şişlik & $\begin{array}{c}\text { Sağ subm. } \\
\text { bölgede } \\
\text { rumuşak kitle }\end{array}$ & - & LAP \\
\hline 17 & $\mathrm{E}$ & $\begin{array}{l}\text { Ağrı ve } \\
\text { şişlik }\end{array}$ & $\begin{array}{l}\text { Stenon kanal } \\
\text { ağzında } \\
\text { eritem }\end{array}$ & - & $\begin{array}{l}\text { Parotideal } \\
\text { duktal } \\
\text { sialolith }\end{array}$ \\
\hline 18 & $\mathrm{E}$ & - & - & $\begin{array}{c}\text { Submandibular } \\
\text { bölg. } \\
\text { kalsifikasyon. }\end{array}$ & $\begin{array}{l}\text { Bez ile ilgili } \\
\text { olmayan } \\
\text { kalsifikasyon }\end{array}$ \\
\hline 19 & $\mathrm{~K}$ & $\begin{array}{l}\text { Ağrı ve } \\
\text { şişlik }\end{array}$ & $\begin{array}{l}\text { Palpasyonda } \\
\text { sert kitle }\end{array}$ & $\begin{array}{l}\text { Submandibular } \\
\text { bölg. } \\
\text { kalsifikasyon }\end{array}$ & $\begin{array}{c}\text { Submandibular } \\
\text { parankimal } \\
\text { sialolith ve } \\
\text { bozulma }\end{array}$ \\
\hline
\end{tabular}

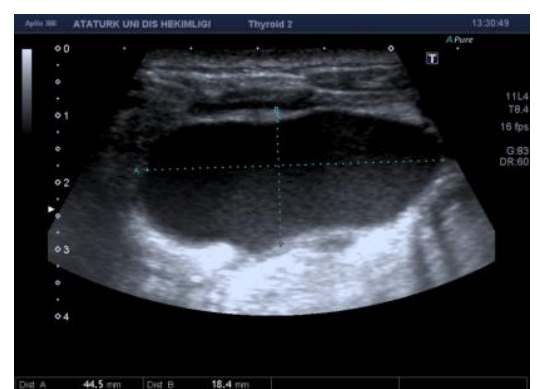

Şekil 2. Sublingual gland ile ilişkili kistik lezyona (ranula) ait ultrason görüntüsü. 


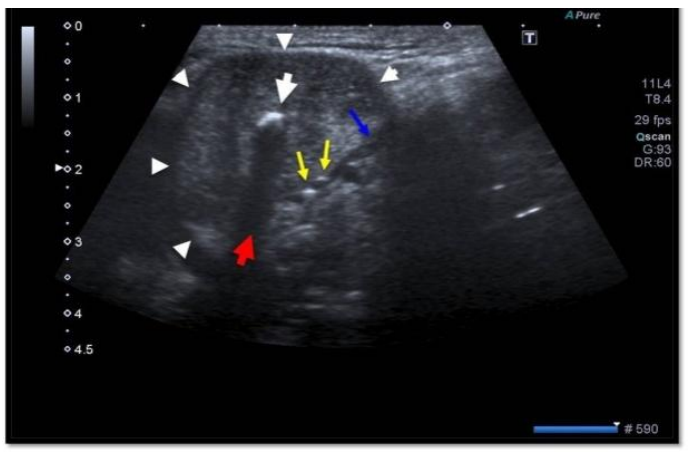

Şekil 3. Submandibular gland içerisinde tespit edilen kalsifikasyona(sialolithiahis) ait ultrason görüntüsü.

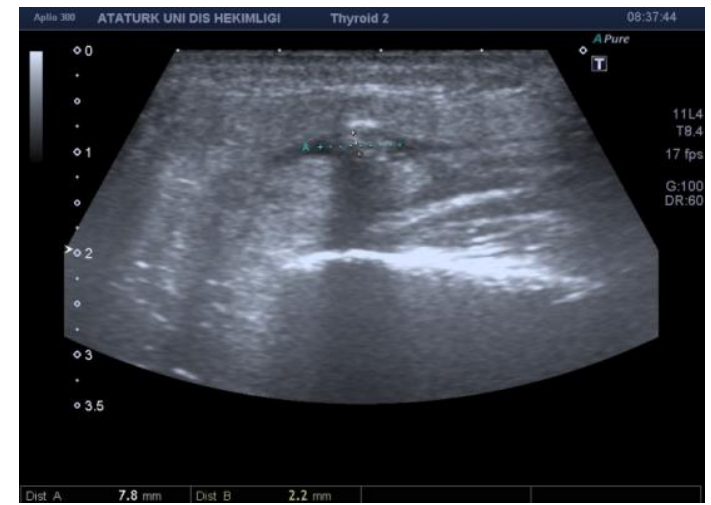

Şekil 4. Parotis bezi ile ilişkili Stenon kanalında kalsifikasyona(sialolithiahis) ait ultrason görüntüsü.

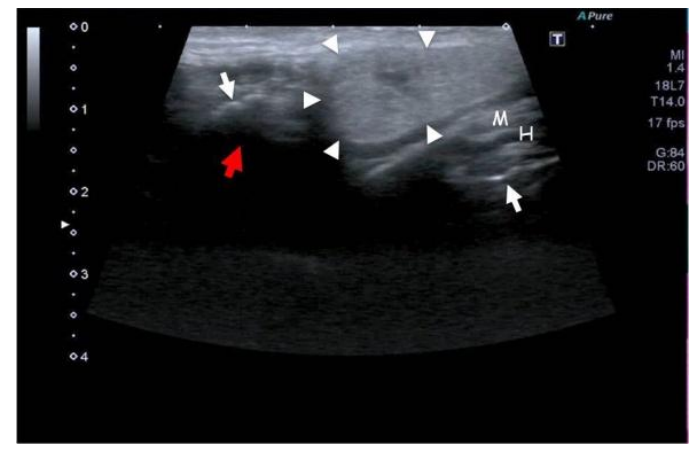

Şekil 5. Submandibular gland ile ilişkili olmayan kalsifikasyona ait ultrason görüntüsü.

\section{TARTIŞMA VE SONUÇ}

Ağız sağlığı genel sağlıktan ayrı düşünülemez. Bu nedenle diş hekimliği, sadece dişlerle değil, ağız ve çevre dokularıyla da ilgili bir bilimdir. Diş hekimliğinin bir uzmanlık dalı olan Ağız Diş ve Çene Radyolojisi maxillofasial görüntüleme alanında çağın gerektirdiği son teknolojik gelişimleri yakalamalıdır. Günümüzde konvansiyonel diş ve çene röntgenlerinin yanı sıra, bilgisayarlı tomografi, manyetik rezonans görüntüleme, ultrasonografi gibi ileri görüntüleme yöntemleri de diş hekimliği radyolojisinde gittikçe daha sık kullanılmaktadır.

Ultrasonografi uygulanması pratik ve invaziv olmayan, ucuz maliyetli bir tekniktir. Kas kalınlığını ölçmede doğru bir metot olup yüksek çözünürlüklü problar ile yüzeysel dokuların yapısal ve patolojik özellikleri bu teknikle detaylı şekilde gösterilebilmektedir. Doppler ultrason klinikte kan akışının varlığı ve yönünü, damarların stenoz veya okluzyonunu, organların perfüzyonunu ve tümör vaskülaritesini değerlendirmek için kullanılmaktadır. Ayrıca Doppler ultasonun küçük ve yavaş akışları bile tespit edebilme, dalga formu ve analizi ile arterleri venlerden ayırma ve kan akımını sayısallaştırabilme özellikleri vardır. Bu özellikleri nedeniyle Doppler sonografi oral ve maksillofasiyal bölgede tükürük bezlerinin değerlendirilmesi, lenf nodu metastazlarının değerlendirilmesi, çiğneme kaslarının değerlendirilmesi, cerrahi operasyonların tasarımı, ve anatomik yapıların incelenmesi gibi birçok alanda kullanılmış ve tanısal açıdan yararlı olduğu gösterilmiştir. Doppler ultrasonografinin kolay uygulanabilmesi, bilinen bir yan etkisinin olmaması, iyonize radyasyon içermemesi ve belirli bir damarı sayısal özellikleri (akış hızı ve indeksler) ile gösterebilmesi avantajlarına dikkat çekilmektedir. Bu özellikleriyle hamile hastalarda, çocuklarda veya radyoterapi görmüş ve tükürük bezi parankimi etkilenmiş hastalarda da güvenle kullanılabilir.

Ultrasonografi özellikle yüzeysel dokuların incelenmesinde dinamik ve kolay uygulanabilen bir görüntüleme tekniğidir. Yüksek frekanslı lineer problar(7,5-12 MHz) ile kombine edilen modern ultrasonografi cihazları birçok düzlemde yüksek çözünürlüklü görüntüler sağlar. ${ }^{2}$ Son zamanlarda modern diş hekimliği radyolojisi $B T, M R G$, Sintigrafi ve USG gibi birçok ileri görüntüleme tekniklerini kullanmaktadır. ${ }^{3}$ Diş Hekimliğinde USG maxillofasial bölge fraktürlerinin saptanmasında ${ }^{4}$, servikal lenfadenopatinin değerlendirilmesinde ${ }^{5}$, baş ve boyun bölgesindeki çeşitli yumuşak doku kitlelerinin incelenmesinde ${ }^{5}$, çiğneme ve boyun kaslarının değerlendirilmesinde ${ }^{6,7}$, Temporomandibular eklemin incelenmesinde ${ }^{8}$, periapikal lezyonların değerlendirilmesinde ${ }^{9,10}$ ve tükürük bezlerinin incelenmesinde kullanılmaktadır ve daha birçok alanda

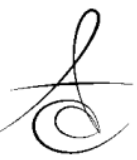


kullanılmaya devam edecektir. USG power doppler ve renkli doppler özellikleriyle lezyonlardaki kan akışının ve vaskülarizasyonun tanımlanmasına olanak verir. ${ }^{2}$

Tükürük bezlerinin görüntülemesinde kontrastlı veya kontrastsız $B T$, kontrastlı veya kontrastsız MRG görüntüleme, sialografi ve MRG sialografi ve ultrasonun klinik verilere bağı olarak uygulanması önerilmektedir. ${ }^{11}$ Yousem ve arkadaşlarına göre ultrasonografi yüzeysel tükürük bezi lezyonlarının görüntülenmesinde BT ve MRG'nin yerini almaktadır. ${ }^{12}$ Bu bağlamda ultrasonografinin non-invaziv bir yöntem olduğu ve iyonize radyasyon içermediği de göz önünde bulundurulmalıdır. Avrupa ve Asya'da ultrasonografi baş boyun bölgesindeki yumuşak dokuların, lenf bezlerinin ve tükürük bezlerinin görüntülenmesinde en yaygın olarak kullanılan yöntem olarak kabul edilir. ${ }^{13}$ Baş boyun bölgesi kompleks bir anatomik yapıya sahip olduğundan dolayı bu bölgedeki yapıların patolojilerinin sonografik özelliklerinin de bilinmesi bir ön koşuldur. Akut enflamasyonlarda tükürük bezleri ultrasonografide artmış kan akımıyla genis hipo-ekoik alanlar şeklinde görülürken, kronik enflamasyonlarda aksine küçülmüş ve homojen olmayan hipo-ekoik alanlar içeren bir görüntüye sahip olur. Taşlar belirgin hiper-ekoik çizgiler veya noktalar şeklinde görülür. Kistler sınırları belirgin an-ekoik alanlar şeklinde görülürken, benign veya malign tümörler çok çeşitli görüntüler verebilir. Tabii ki bu patolojiler değerlendirilirken doppler ultrason ile patolojilerin vaskülarizasyonu ve kan akımı da mutlaka değerlendirilmelidir.

Bazı hastaların dental muayeneleri için alınan panoramik radyografilerde fokal through içerisinde yer alan kalsfikasyonlar görülebilir. Fakat bu görüntüler iki boyutlu olduğu için bu yapıların tam olarak lokalizasyonları yapılamaz. Ayrıca çok önemli bir problem de yumuşak dokuların görüntülenememesi ve bu kalsifikasyonların yumuşak dokularla ilişkisinin tespit edilememesidir. Nitekim mevcut çalışmamızda da panoramik radyografilerinde sialolithiasis ön tanıSı konulan 11 kalsifikasyon vakasının 3'ünün USG incelemesi sonucunda tükürük bezleri ile ilişkili olmadıkları tespit edilmiştir. Ayrıca USG yumuşak dokuları net bir şekilde görüntüleyebilme özelliği sayesinde, tükürük bezi taşlarının bez parankiminde veya kanallarında olduğu konusunda net bilgiler sağlamıştır. İlerleyen teknolojilerle beraber USG'nin tükürük bezi taşları ve patolojilerinin bir çoğunun teşhisi için en iyi yöntem olduğu kabul görmektedir. ${ }^{14-}$
${ }^{16}$ Klinik bulgularla kombine edildiğinde USG hekime normal ve patolojik tükürük bezlerinin hızlı bir şekilde incelenmesine olanak verir. Ayrıca intra-oral USG tekniği ile Wharton kanalı intra-oral olarak da iyi bir şekilde incelenebilir ve küçük boyutlu taşlar tespit edilebilir. Ayrıca doppler ultrason sayesinde kan akımı ve vaskülarizasonun incelenebilmesi solid ve kistik lezyonları ayırt etmede katkı sağlar. Bizim çalışmamızda 3 hastamızda panoramik radyografide herhangi bir bulgu tespit edilemezken, USG'de kistik lezyon tespit edilmiş ve doppler inlemeyle bu lezyonların yalnızca çeperinde kanlanma olduğu tespit edilmiş ve kistik lezyon olan ranula teşhisi konulmuştur.

Fakat USG'nin de bazen tükürük bezlerinin görüntülenmesinde bazı sınırlılıkları olabilir. Şöyle ki, parotis bezinin derin lobu olan infra-mandibular parçası ve submandibular bezin derin loblarını USG ile görüntülemek zordur. ${ }^{14}$ Böyle vakalarda USG beraberinde vakanın durumuna göre MRG veya BT kullanmak uygun olabilir.

Sonuç olarak, tükürük bezlerinin incelemesinde kolay, non invaziv, iyonize radyasyon içermeyen ve ucuz bir teknik olan USG, hastaların 18'inde(\%95) kesin tanıya katkı sağlamış olup, bu anlamda konvansiyonel radyografi tekniklerine olan üstünlüğü tartışmasızdır. Sadece konvansiyonel radyografi tekniklerine değil aynı zamanda USG gibi ileri görüntüleme tekniklerine de vakıf donanımlı Ağız Diş ve Çene Radyolojisi uzmanlarının yetişmesiyle, diş hekimliğinde ileri görüntüleme yöntemlerinin gerekli vakalarda rutin olarak kullanımı artırımalıdır.

\section{KAYNAKLAR}

1. Çağlayan F, Çakur B, Harorlı A. Tükürük bezlerinin radyografik tanı yöntemleri ve sialografi. Atatürk Üniv Diş Hek Fak Derg 2003;13:99-111.

2. Oeppen RS, Gibson D, Brennan PA. An update on the use of ultrasound imaging in oral and maxillofacial surgery. $\mathrm{Br} \mathrm{J}$ Oral Maxillofac Surg 2010;48:412-8.

3. Kumar S, Mahabob M. Ultrasound in dentistry- a review. JIADS 2010;1:44-5.

4. Akizuki $H$, Yoshida $H$, Michi $K$ Ultrasonographic evaluation during reduction of zygomatic arch fractures. J Craniomaxillofac Surg 1990; 18: 263-6. 
5. Ahuja AT, Ying M, Ho SY, Antonio G, Lee YP, King $A D$, Wong $K T$. Ultrasound of malignant cervical lymph nodes. Cancer Imaging 2008; 25:48-56.

6. Uchida $Y$, Motoyoshi M, Shigeeda T, Shinohara A, Igarashi $Y$, Sakaguchi M, Shimizu N. Relationship between masseter muscle size and maxillary morphology. Eur J Orthod 2011;33: 654-9.

7. Naser-ud-Din S, Thoirs K, Sampson WJ. Ultrasonography, lateral cephalometry and 3D imaging of the human masseter muscle. Orthod Craniofac Res 2011;14:33-43.

8. Bas B, Yılmaz N, Gökce E, Akan H. Diagnostic value of ultrasonography in temporomandibular disorders. J Oral Maxillofac Surg 2011; 69:130410.

9. Raghav N, Reddy SS, Giridhar AG, Murthy S, Yashodha Devi BK, Santana N, Rakesh N, Kaushik A. Comparison of the efficacy of conventional radiography, digital radiography, and ultrasound in diagnosing periapical lesions. Oral Surg Oral Med Oral Pathol Oral Radiol Endod 2010;110:379-85.

10. Tikku AP, Kumar S, Loomba K, Chandra A, Verma $P$, Aggarwal R. Use of ultrasound, color Doppler imaging and radiography to monitor periapical healing after endodontic surgery. J Oral Sci 2010;52:411-6.

11. Bialek EJ, Jakubowski W, Zajkowski P, Szopinski $\mathrm{KT}$, Osmolski A. US of the major salivary glands: anatomy and spatial relationships, pathologic conditions, and pitfalls. Radiographics 2006;26:745-63.

12. Yousem DM, Kraut MA, Chalian AA. Major salivary gland imaging. Radiology 2000;216:19-29.

13. Alyas F, Lewis K, Williams M, et al. Diseases of the submandibular gland as demonstrated using high resolution ultrasound. $\mathrm{Br}$ ] Radiol 2005;78:362-9.

14. Zengel $P$, Schr€otzlmair $F$, Reichel $C$, et al: Sonography: The leading diagnostic tool for diseases of the salivary glands. Semin Ultrasound CT MR 2013;34:196.

15. Yoshimura $Y$, Inoue $Y$, Odagawa $T$ : Sonographic examination of sialolithiasis. J Oral Maxillofac Surg 1989;47:907.

16. Cağlayan F, Sümbüllü MA, Miloğlu O, Akgül HM. Are all soft tissue calcifications detected by conebeam computed tomography in the submandibular region sialoliths? J Oral Maxillofac Surg 2014;72:1531.e1-6.

\section{Yazışma Adresi:}

Doç. Dr. Fatma ÇAĞLAYAN

Atatürk Üniversitesi Diş Hekimliği Fakültesi Ağız, Diş ve Çene Radyolojisi AD.

25240 Erzurum / TÜRKIYYE

Telefon numarasI: +90 442 2360944-1819

Fax numarası: +90 4422360945

E-mail: facagla@gmail.com 